\title{
Aza-Crown Ethers with Quinone Side Chains: Synthesis, Complexation, and Protonation
}

\section{Tadeusz Ossowski and Hermann Schneider*}

Max-Planck-Institut für biophysikalische Chemie, Am Faßberg, D-3400 Göttingen

Received January 24, 1990

Key Words: Crown ethers, quinoid / Alkali metal complexes / Alkaline earth metal complexes

The synthesis and spectroscopic investigation of aza-crown ethers with anthraquinone- and 1-aminoanthraquinone-functionalized side chains are described. Cation-induced shifts in the UV/VIS absorption spectra of the ligands dissolved in propylene carbonate are observed only for $\mathrm{Li}^{+}$among the alkali metal ions and for $\mathrm{Mg}^{2+}$ among the alkaline earth metal ions as well as for $\mathrm{Ag}^{+}$and $\mathrm{Tl}^{+}$. Only hypsochromic shifts of the absorption spectra of anthraquinone-bearing aza-crown ethers are observed on protonation. The variations of the extinction coefficients are discussed with respect to the sequence of protonation of the different amino groups.
The binding properties of macrocyclic polyethers are markedly altered when additional groups are attached as pendant arms to a macromolecular ring ${ }^{1,2)}$. When quinone ${ }^{33}$, anthraquinone $e^{4,5)}$, nitrobenzene ${ }^{6,7)}$, or other electrochemically active groups ${ }^{8-10)}$ are bound to a crown ether, its cation-binding property is enhanced under electrochemically reducing conditions, because radical species are formed. The group of redox-active macrocycles has been studied in membrane transport experiments as electrochemically switchable ionophores $^{5,11-13)}$.

Our attention is focused on aza-crown ethers with anthraquinone and 1-aminoanthraquinone as pending arms, because these quinones play an important role in biological systems and as antitumor agents ${ }^{14-16}$.

We have investigated aza-crown ethers containing side chains and their metal ion complexes, because $N$-pivot-substituted crown ethers generally display a stronger tendency toward cation binding than the $C$-pivot-substituted analogs ${ }^{6)}$. In this paper we report on the syntheses and electrochemical properties of several branched monoaza-18-

Scheme 1

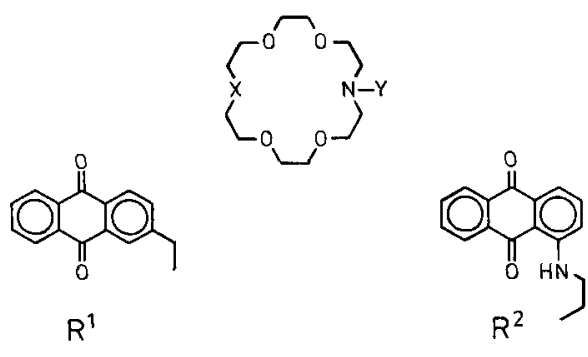

\begin{tabular}{cll}
$X$ & $Y$ & Compound \\
\hline$N R^{1}$ & $R^{1}$ & $\left(\right.$ AQme) ${ }_{2} A_{2} 18 C 6$ \\
0 & $R^{2}$ & (AQNet) $A_{18 C 6}$ \\
$N H$ & $R^{2}$ & (AQNet) $A_{2} 18 C 6$ \\
$N R^{2}$ & $R^{2}$ & (AQNet) ${ }_{2} A_{2} 18 C 6$
\end{tabular}

crown-6 and 1,10-diaza-18-crown-6 compounds. The structures and acronyms are shown in Scheme 1.

\section{Results and Discussions}

Syntheses of Ligands: The ligand 1,4,7,10,13-pentaoxa-16azacyclootadecane or monoaza-18-crown-6, A18C6, has been prepared according to the method proposed by Maeda et al. ${ }^{17} ;$, 1,4,10,13-tetraoxa-7,16-diazacyclooctadecane or diaza-18-crown-6, $\mathrm{A}_{2} 18 \mathrm{C} 6$, is commercially available (Merck). The preparation of 1-[(2-bromoethyl)amino]anthraquinone (AQNetBr) is illustrated in Scheme 2. 1-Fluoroanthraquinone has been obtained in $57 \%$ yield ${ }^{18)}$. Treatment of this compound with 2-hydroxyethylamin affords 1-[(2hydroxyethyl)amino] anthraquinone in $100 \%$ yield which is brominated with $\mathrm{HBr}$ in acetic acid to furnish in $90 \%$ yield $\mathrm{AQNetBr}$ as a red powder. Previously, ethyl methyl ketone has been used as medium for the reaction of aza-crown ethers with the brominated anthraquinone ${ }^{19,20)}$, but we have achieved an increase in yield by more than $50 \%$ by performing the reaction in toluene at $140^{\circ} \mathrm{C}$. The products are purified by column chromatography with aluminum oxide or by flash chromatography with silica gel. The compounds (AQNet)A18C6, (AQNet) $A_{2} 18 \mathrm{C} 6, \quad(\mathrm{AQNet})_{2} \mathrm{~A}_{2} 18 \mathrm{C} 6$, or (AQme) ${ }_{2} \mathrm{~A}_{2} 18 \mathrm{C} 6$ have been prepared from $\mathrm{AQNetBr}$ or

Scheme 2<smiles>Nc1cccc2c1C(=O)c1ccccc1C2=O</smiles>

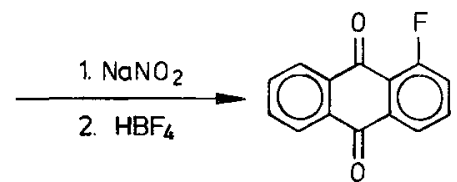<smiles>O=C1C(=O)c2cccc(NCCCBr)c2C(=O)c2ccccc21</smiles> 
$\mathrm{AQNmeBr}$, respectively, as well as the corresponding crown ethers.

Electronic Spectra of 1-Aminoanthraquinone (AQN) Derivatives: The spectrum of $\mathrm{AQN}$ consists in the visible region of a $\pi \rightarrow \pi^{*}$ absorption band due to intramolecular electron transfer from the substituted amino group to the AQ nucleus. When the electron-donating character of a substituent at $\mathbf{C}-1$ of the anthraquinone increases, the absorption maximum is shifted to longer wavelengths ${ }^{21-23)}$. Table 1 shows the results for AQN and its substituted compounds studied in propylene carbonate (PC). The differences in the azacrown ethers exert no influence on the peak wavelength position, because the intramolecular bonding between the hydrogen atom of the amino group and the adjacent carbonyl group of the quinone is unaffected (Scheme 3).

Scheme 3

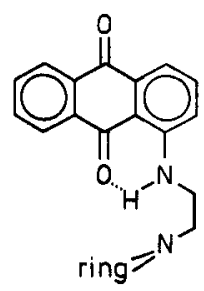

Table 1. Peak wavelength $\lambda_{\max }[\mathrm{nm}]^{\text {a) }}$ and molar extinction coefficient $\varepsilon\left[\mathrm{M}^{-1} \mathrm{~cm}^{-1}\right]^{\text {b) }}$ of 1-aminoanthraquinone (AQN) and some of its derivatives ${ }^{\mathrm{c}}$ in propylene carbonate solutions at $25^{\circ} \mathrm{C}$

\begin{tabular}{lll} 
& $\lambda_{\max }$ & $\lg \varepsilon$ \\
\hline AQN & 470 & 3.80 \\
AQNetBr & 493 & 3.84 \\
(AQNet)A18C6 & 510 & 3.71 \\
(AQNet)A $18 C 6$ & 510 & 3.76 \\
(AQNet) ${ }_{2} \mathrm{~A}_{2} 18 \mathrm{C} 6$ & 510 & 4.05
\end{tabular}

a) $\Delta \lambda_{\max }= \pm 2 \mathrm{~nm} .-{ }^{\text {b) }} \Delta \lg \varepsilon= \pm 0.007 .{ }^{\text {c) }}$ Concentrations ca.
$5 \cdot 10^{-5}$.

Metal Ion Complexes: When alkali metal and alkaline earth metal perchlorates are added to a solution of (AQNet)A18C6 in PC, only $\mathrm{LiClO}_{4}$ and $\mathrm{Mg}\left(\mathrm{ClO}_{4}\right)_{2}$ produce substantial shifts of the absorption band. Also for $\mathrm{AgClO}_{4}$ and $\mathrm{TlClO}_{4}$ shifts of comparable magnitude are found causing a reduction in the molar extinction coefficients (Table 2). The cation-induced hypsochromic changes in the band position are shown in Figure 1. In order to discuss the results in more detail, one should know the binding strength of cations in the crown ether rings. Since stability constants for complexes of $\mathrm{A} 18 \mathrm{C} 6$ with a alkali and alkaline earth cations are known in $\mathrm{PC}^{24)}$ and should not differ substantially from stability constants of corresponding (AQNet)A18C6 complexes, it is possible to estimate the percentage of complexed (AQNet)A18C6 in $5 \cdot 10^{-5} \mathrm{M}$ ligand solutions with a hundredfold excess of metal salt. Since the stability constants of the complexes are large the cations listed in Table 2 are binding more than 98\% of (AQNet)A18C6 in solution. Although the stability constant of the complex of
A18C6 with $\mathrm{Tl}^{+}$in $\mathrm{PC}$ is not available, a comparison with $\mathrm{A}_{2} 18 \mathrm{C} 6[\text { or }(2,2)]^{25)}$ suggests that $\mathrm{Tl}^{+}$complexes effectively all available (AQNet)A18C6 molecules. Therefore, the maximum wavelength $\lambda_{\max }$ and the molar extinction coefficent $\varepsilon$ in Table 1 are properties of the metal ion complexes with (AQNet)A18C6. Bearing in mind the experimental error of $\pm 2 \mathrm{~nm}$ in $\lambda_{\max }$ and \pm 0.007 in $\lg \varepsilon$, only $\mathrm{Li}^{+}, \mathrm{Mg}^{2+}, \mathrm{Ag}^{+}$, and $\mathrm{Tl}^{+}$interact to a measurable extent with the chromophoric group. Since $\mathrm{Li}^{+}$and $\mathrm{Mg}^{2+}$ do not fill the cavity of the ring and interact only with the ether oxygen atoms, the conformational flexibility of the amino group in the ring is hardly reduced. Therefore, a position of the chromophore near the ring is possible, and the cations influence the hydrogen bond between the carbonyl group of the quinone and the hydrogen atom of the adjacent amino group (Scheme 3). The silver and the thallous ion are tightly held in the aza-crown ring, in the case of $\mathrm{Ag}^{+}$by a strong interaction with the nitrogen atom. Hence, the nitrogen lone pair points to the metal ion in the ring, and the AQN group is located externally. The observed hypsochromic shifts of the absorption bands in Table 2 are opposite to the variation of $\lambda_{\max }$ in Table 1 with increasing electronegativity of the substituents.

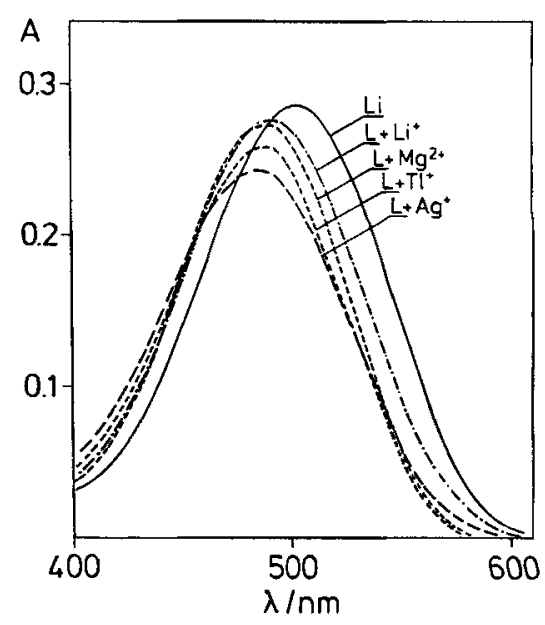

Figure 1. Changes of the absorbance $A$ of (AQNet)A18C6 in the presence of $\mathrm{LiClO}_{4}, \mathrm{Mg}\left(\mathrm{ClO}_{4}\right)_{2}, \mathrm{AgClO}_{4}$, and $\mathrm{TlClO}_{4}$ [hundredfold excess of salt over $5.3 \cdot 10^{-5} \mathrm{M}(\mathrm{AQNet}) \mathrm{A} 18 \mathrm{C} 6$ in PC]

The influences exerted by cations on the absorption spectra of (AQNet) $\mathrm{A}_{2} 18 \mathrm{C} 6$ and $(\mathrm{AQNet})_{2} \mathrm{~A}_{2} 18 \mathrm{C} 6$ are very similar to those found for (AQNet)A18C6. In the solutions studied nearly all ligand molecules are complexed by cations. The strongest hypsochromic shifts are observed with $\mathrm{Mg}^{2+}$, $\mathrm{Ag}^{+}$, and $\mathrm{Tl}^{+}$(Table 2). The absorption spectrum of (AQme) $)_{2} \mathrm{~A}_{2} 18 \mathrm{C} 6$ consists of at least three $\pi \rightarrow \pi^{*}$ bands which are shifted only by the interaction of $\mathrm{AgClO}_{4}$ (Figure 2). All other salts listed in Table 2 have an only negligible effect on the peak positions of the absorption bands of (AQme) ${ }_{2} \mathrm{~A}_{2} 18 \mathrm{C} 6$.

Protonation of the 1-Aminoanthraquinone Group: The addition of trifluoromethanesulfonic acid ${ }^{26)}$ to $\mathrm{PC}$ solutions of $(\mathrm{AQNet})_{2} \mathrm{~A}_{2} 18 \mathrm{C} 6$ causes a hypsochromic shift in the visible absorption spectra. In the corresponding spectra of the sub- 
Table 2. Peak wavelength $\lambda_{\max }[\mathrm{nm}]^{\text {a) }}$ and molar extinction coefficient $\varepsilon\left[\mathrm{M}^{-1} \mathrm{~cm}^{-1}\right]^{\mathrm{b})}$ of an anthraquinone side chain attached to aza-crown ethers in propylene carbonate solutions containing various metal cations at $25^{\circ} \mathrm{C}^{\mathrm{c})}$

\begin{tabular}{|c|c|c|c|c|c|c|}
\hline & \multicolumn{2}{|c|}{ (AQNet)A18C6 } & \multicolumn{2}{|c|}{ (AQNet) $A_{2} 18 \mathrm{C} 6$} & \multicolumn{2}{|c|}{ (AQNet) ${ }_{2} \mathrm{~A}_{2} 18 \mathrm{C} 6$} \\
\hline & $\lambda_{\max }$ & $\lg \varepsilon$ & $\lambda_{\max }$ & $\lg \varepsilon$ & $\lambda_{\max }$ & $\lg \varepsilon$ \\
\hline - & 510 & 3.71 & 510 & 3.76 & 510 & 4.05 \\
\hline $\mathrm{LiClO}_{4}$ & 500 & 3.70 & 504 & 3.77 & 503 & 4.05 \\
\hline $\mathrm{NaClO}_{4}$ & 513 & 3.72 & 505 & 3.76 & 513 & 4.04 \\
\hline $\mathrm{KClO}_{4}$ & 511 & 3.71 & 505 & 3.76 & 512 & 4.03 \\
\hline $\mathrm{CsClO}_{4}$ & 513 & 3.73 & - & - & 504 & 4.04 \\
\hline $\mathrm{Mg}\left(\mathrm{ClO}_{4}\right)_{2}$ & 493 & 3.71 & 491 & 3.74 & 483 & 4.05 \\
\hline $\mathrm{Ca}\left(\mathrm{ClO}_{4}\right)_{2}$ & 510 & 3.71 & 508 & 3.76 & 502 & 4.10 \\
\hline $\operatorname{Sr}\left(\mathrm{ClO}_{4}\right)_{2}$ & 510 & 3.71 & 504 & 3.77 & 505 & 4.10 \\
\hline $\mathrm{Ba}\left(\mathrm{ClO}_{4}\right)_{2}$ & - & - & 504 & 3.76 & 502 & 4.05 \\
\hline $\mathrm{AgClO}_{4}$ & 490 & 3.62 & 492 & 3.73 & 491 & 4.06 \\
\hline $\mathrm{TIClO}_{4}$ & 493 & 3.65 & 500 & 3.73 & 498 & 4.04 \\
\hline
\end{tabular}

a) $\Delta \lambda_{\max }= \pm 2 \mathrm{~nm} .-{ }^{\text {b) }} \Delta \lg \varepsilon= \pm 0.007 .-{ }^{\text {c) }}$ Concentrations of crown ether ligands ca. $5 \cdot 10^{-5} \mathrm{M}$. Hundredfold excess of salt.

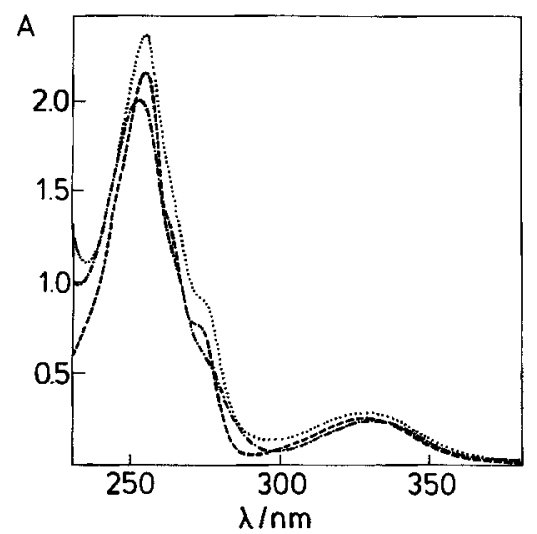

Figure 2. Cation-induced spectral changes of $(\mathrm{AQme})_{2} \mathrm{~A}_{2} 18 \mathrm{C} 6$ in PC $(---)$, in the presence of $\mathrm{LiClO}_{4}(\cdots \cdots), \mathrm{KClO}_{4}(-\cdots-)$, and $\mathrm{AgClO}_{4}(-\cdot-)$ [hundredfold excess of salt over $3.0 \cdot 10^{-5} \mathrm{M}$ (AQme) ${ }_{2} \mathrm{~A}_{2} 18 \mathrm{C} 6 ; A$ : absorbance]

stituted crown ethers the intensity of the band at $510 \mathrm{~nm}$ decreases with increasing acid concentration, and a new band at $482 \mathrm{~nm}$ appears. An isosbestic point is observed at $494 \mathrm{~nm}$ (Figure 3). The molar extinction coefficient determined at the wavelength of the new band increases with increasing ratio of the acid-to-ligand concentration and passes through a maximum value at a concentration ratio equal to one for the monoaza-crown ligand and at a ratio equal to two for the diaza-crown compounds (Figures 4a, $\mathrm{b}$, c). The new band at $482 \mathrm{~nm}$ and the increase of its extinction $\varepsilon_{482}$ is correlated with the protonation of nitrogen in the aza-crown ring. The results for (AQNet) $\mathrm{A}_{2} 18 \mathrm{C} 6$ allow a distinction to be made between the protonation of the various nitrogen atoms (Figure $4 \mathrm{~b}$ ). In a first step, the secondary ring nitrogen atom is protonated, and the molar extinction coefficient of the ligand remains constant until the less basic tertiary nitrogen with the AQNet group is protonated. The extinction coefficient $\varepsilon_{510}$, determined at $510 \mathrm{~nm}$, the wavelength of the original absorption band, changes with the acid concentration in the same way as $\varepsilon_{482}$. Only $\varepsilon_{510}$ of (AQNet)A18C6 decreases smoothly with increasing acid concentration. When the nitrogen atoms of the crown moiety are protonated and the acid concentration is continuously increased, the preceding increase in the absorbance at $482 \mathrm{~nm}$ changes to decrease (Figure $4 \mathrm{a}, \mathrm{b}, \mathrm{c}$ ), and the absorption curves cease to pass through the isosbestic point (Figure 3). A new band with a wave-like peak also appears at $482 \mathrm{~nm}$ which belongs to the protonated amino group of the aminoanthraquinone side chain.

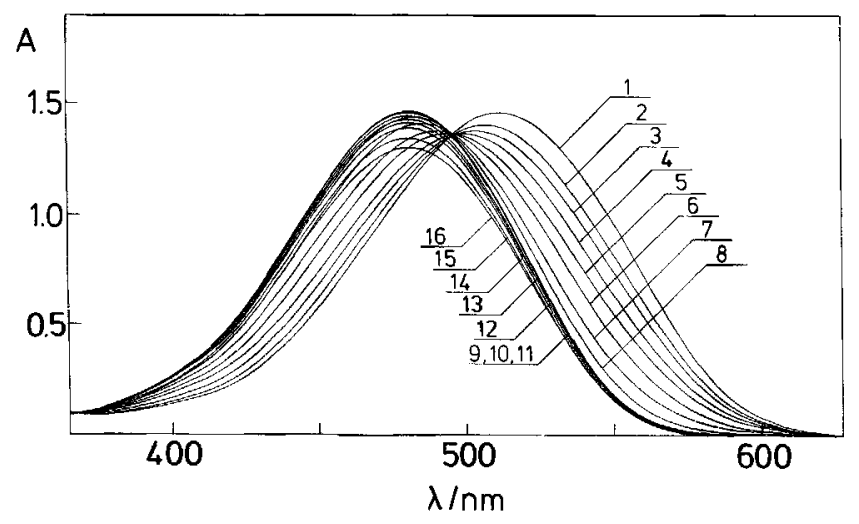

Figure 3. Spectral changes of (AQNet) ${ }_{2} \mathrm{~A}_{2} 18 \mathrm{C} 6$ in the presence of trifluoromethanesulfonic acid [molar ratio of acid to $1.3 \cdot 10^{-4} \mathrm{M}$ (AQNet) ${ }_{2} \mathrm{~A}_{2} 18 \mathrm{C} 6$ in PC: 0.0 (1); 0.25 (2); $0.5(3) ; 0.75$ (4); 1.00 (5); $1.25(6) ; 1.50(7) ; 1.75(8) ; 2.00(9) ; 2.25(10) ; 2.50(11) ; 3.00(12) ; 3.50$ (13); $4.00(14) ; 4.50(15) ; 7.00(16)]$
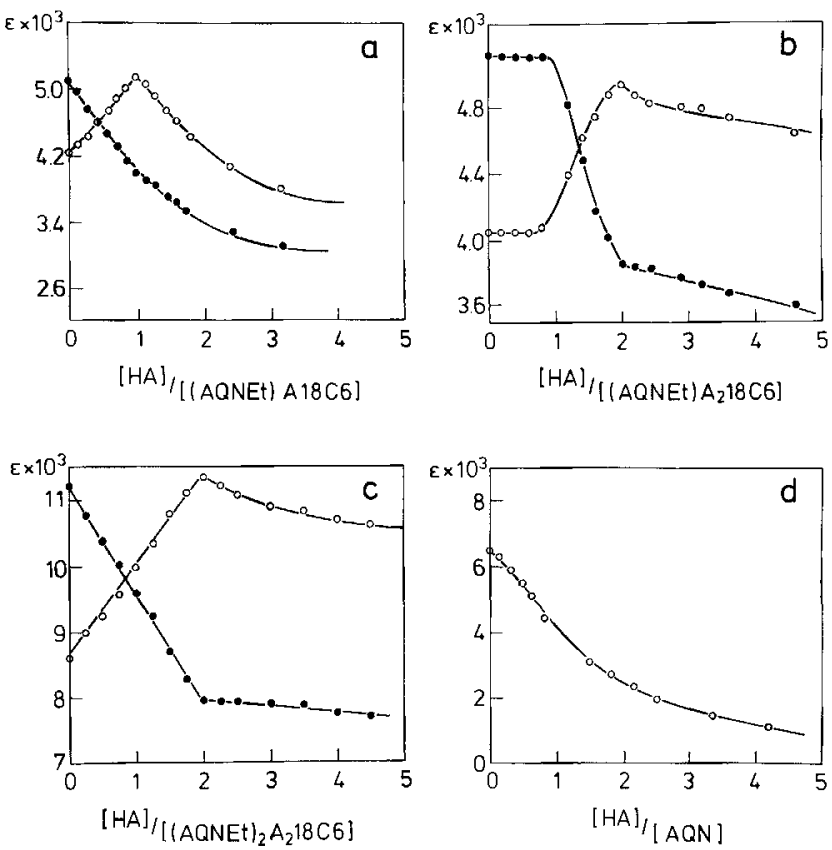

Figure 4. Changes in the molar extinction coefficients $\varepsilon$ of aminoanthraquinones with the molar ratio of trifluoromethanesulfonic acid (HA) to substituted aza-crown ethers a) (AQNet)A18C6, b) (AQNet) $\left.\mathrm{A}_{2} 18 \mathrm{C} 6, \mathrm{c}\right)(\mathrm{AQNet})_{2} \mathrm{~A}_{2} 18 \mathrm{C} 6$ : at $482 \mathrm{~nm}(\mathrm{o})$, and at 510 $\mathrm{nm}(\bullet)$, d) extinction coefficient of $A Q N$ : at $470 \mathrm{~nm}$ 


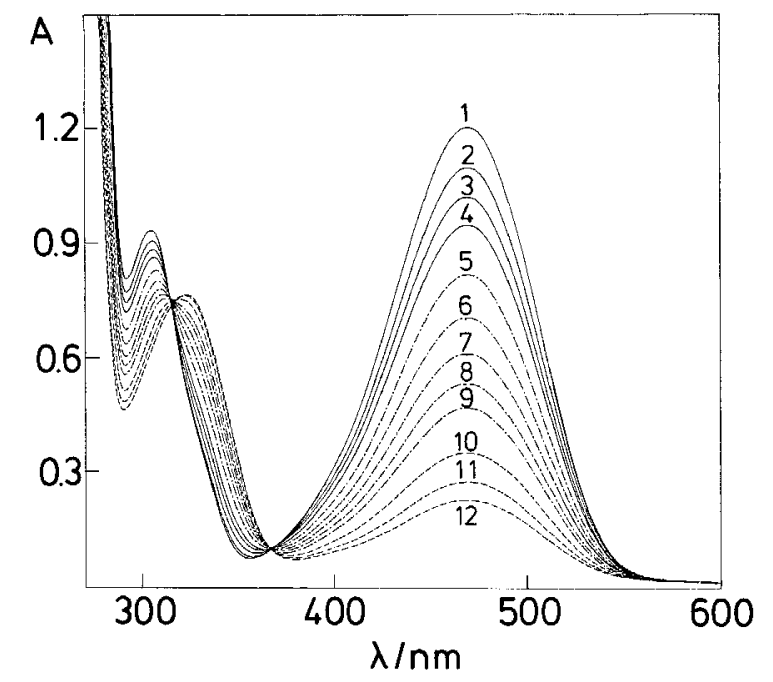

Figure 5. Spectral changes of 1-aminoanthraquinone in the presence of trifluoromethanesulfonic acid [molar ratio of acid to 1.8 . $10^{-4} \mathrm{M}$ AQN in PC: 0.0 (1); 0.33 (2); $0.50(3) ; 0.67(4) ; 0.84(5) ; 1.17$ (6); 1.50 (7); 1.84 (8); 2.17 (9); 2.51 (10); 3.34 (11); 4.18 (12)]

Also the protonation of $\mathrm{AQN}$ is observed as a decrease in absorbance (at $470 \mathrm{~nm}$, Figure $4 \mathrm{~d}$ ), the wavelength of the absorption maximum remaining uneffected (Figure 5).

\section{Experimental}

Materials: 1,10-Diaza-18-crown-6 ( $\left.\mathrm{A}_{2} 18 \mathrm{C} 6\right)$, a commercial sample (Merck), was used without further purification. Monoaza-18crown-6 (A18C6) was prepared according to the methods described in the literature ${ }^{17)}$. 1-Amino-9,10-anthracenedione (Merck), 9,10anthracenedione (Fluka), 2-(bromomethyl)-9,10-anthracenedione (AQmeBr) (Fluka), 2-aminoethanol (Merck), propylene carbonate (PC) (Merck), trifluoromethanesulfonic acid (Merck) were reagent grade chemicals and sufficiently pure to be used directly.

Instrumentation: UV-VIS: Shimadzu UV-240 spectrophotometer equipped with a cell compartment thermostated at $25.00 \pm 0.02^{\circ} \mathrm{C}$. Spectroscopic titrations were performed by adding a solution of trifluoromethanesulfonic acid directly to a solution of the anthraquinone compounds contained in a $1-\mathrm{cm}$ cuvette $(3.8 \mathrm{ml})$, using a Hamilton syringe $(5 \mu \mathrm{l})$. $-{ }^{1} \mathrm{H}$ NMR: Bruker HFX-90 spectrometer, tetramethylsilane (TMS) as internal reference. - Microanalyses: Mikroanalytisches Laboratorium Beller, Göttingen.

1-[(2-Hydroxyethyl)amino]-9,10-anthracenedione (Scheme 2): $2.6 \mathrm{~g}(11.5 \mathrm{mmol})$ of 1 -fluoro-9,10-anthracenedione ${ }^{8)}$ and $10 \mathrm{ml}$ of 2-aminoethanol were heated to $70^{\circ} \mathrm{C}$ for $15 \mathrm{~min}$. During heating, the solution changed its color from yellow to red. The hot solution was poured on ice ( $25 \mathrm{~g})$, the red precipitate separated by filtration, washed with water, and dried at room temperature. $3.6 \mathrm{~g}$ of $1-[(2-$ hydroxyethyl)amino $-9,10$-anthracenedione (yield ca. 100\%) was obtained as a red powder. The crude product was purified by recrystallization from ethanol or by column chromatography on silica gel with acetyl acetate/toluene (1:4) as eluent. $-{ }^{1} \mathrm{H} \mathrm{NMR}\left(\mathrm{CDCl}_{3}\right)$ : $\delta=2.11(\mathrm{~s}, 1 \mathrm{H}) ; 3.55(\mathrm{q}, 2 \mathrm{H}) ; 3.98(\mathrm{t}, 2 \mathrm{H}) ; 7.19(\mathrm{~m}, 2 \mathrm{H}) ; 7.25(\mathrm{~m}$, $3 \mathrm{H}) ; 8.22(\mathrm{~m}, 2 \mathrm{H}) ; 9.86(\mathrm{~s}, 1 \mathrm{H})$.

1-[(2-Bromoethyl)amino]-9,10-anthracenedione: $3.11 \mathrm{~g}$ of crude 1-[(2-hydroxyethyl)amino]-9,10-anthracenedione was dissolved in $50 \mathrm{ml}$ of solution of $\mathrm{HBr}$ in acetic acid $(33 \% \mathrm{w})$. The solution was heated to $80-110^{\circ} \mathrm{C}$ in a closed capsule for $2-4 \mathrm{~h}$. The progress in the reaction was controlled by TLC (silical gel, eluent pyridine/ ethyl acetate/toluene $1.6: 3: 17$ ). The black solution was poured on ice (ca. $300 \mathrm{~g}$ ) and neutralized with aqueous ammonia (25\%) to $\mathrm{pH}=7$. The precipitate thus formed was washed with cold water and dried in the air. The crude product $(3.4 \mathrm{~g}, 90 \%)$ was purified by crystallization from ethanol or by column chromatography on aluminum oxide with toluene/THF (1:1). - ${ }^{1} \mathrm{H}$ NMR $\left(\mathrm{CDCl}_{3}\right)$ : $\delta=3.64(\mathrm{~m}, 4 \mathrm{H}) ; 7.10(\mathrm{~m}, 2 \mathrm{H}) ; 7.59(\mathrm{~m}, 3 \mathrm{H}) ; 8.26(\mathrm{~m}, 2 \mathrm{H}) ; 9.86$ (s, $1 \mathrm{H})$.

7,16-Bis(9,10-dihydro-9,10-dioxo-2-anthracenylmethyl)-1,4,10,13tetraoxa-7,16-diazacyclooctadecane [(AQme $\left.)_{2} \mathrm{~A}_{2} 18 \mathrm{C} 16\right]$ : A suspension of $\mathrm{A}_{2} 18 \mathrm{C} 6(0.10 \mathrm{~g}, 0.38 \mathrm{mmol})$ and $\mathrm{Na}_{2} \mathrm{CO}_{3}(0.40 \mathrm{~g}, 3.77 \mathrm{mmol})$ in freshly destilled acetonitrile $(50 \mathrm{ml})$ was heated at reflux, and a solution of 2-(bromomethyl)-9,10-anthracenedione (AQmeBr) $(0.23 \mathrm{~g}$, $0.76 \mathrm{mmol}$ ) in $25 \mathrm{ml}$ of acetonitrile was added dropwise with efficient stirring. The mixture was heated at reflux for a further $10 \mathrm{~h}$. After cooling to room temp., the insoluble solid was separated by filtration and the filtrate concentrated. The residual crude oil was recrystallized twice from $\mathrm{CH}_{2} \mathrm{Cl}_{2}$ /petroleum ether to give (AQme) ${ }_{2} \mathrm{~A}_{2} 18 \mathrm{C} 6$ as a white-yellow crystalline solid $(0.13 \mathrm{~g}, 60 \%)$. ${ }^{1} \mathrm{H} \mathrm{NMR}\left(\mathrm{CDCl}_{3}\right): \delta=2.65(\mathrm{t}, 8 \mathrm{H}) ; 3.41(\mathrm{~m}, 16 \mathrm{H}) ; 3.70(\mathrm{~s}, 4 \mathrm{H}) ; 7.75$ (s, 2H); $7.71(\mathrm{~m}, 6 \mathrm{H}) ; 8.21(\mathrm{~m}, 6 \mathrm{H})-\mathrm{MS}(70 \mathrm{eV}): \mathrm{m} / \mathrm{z}=703\left[\mathrm{M}^{+}\right]$.

\section{$\mathrm{C}_{42} \mathrm{H}_{42} \mathrm{~N}_{2} \mathrm{O}_{8}$ (702.8) Calcd. C $71.77 \mathrm{H} 6.02 \mathrm{~N} 3.99$ O 18.21} Found C 71.5 H 6.1 N 4.1 O 18.5

1-\{[2-(1,4,10,13-Tetraoxa-7,16-diaza-7-cyclooctadecyl)ethyl $]$ amino -9,10-anthracenedione [(AQNet) $\left.\mathrm{A}_{2} 18 \mathrm{C} 6\right]$ and 7,16-Bis $\{2-$ [ (9,10-dihydro-9,10-dioxo-1-anthracenyl)amino Jethyl $\}$-1,4,10,13-tetraoxa-7,16-diazacyclooctadecane [(AQNet $\left.)_{2} \mathrm{~A}_{2} 18 \mathrm{C} 6\right]$ : A suspension of $0.63 \mathrm{~g}$ (1.96 mmol) of 1-[(2-bromoethyl)amino]-9,10-anthracenedione and $0.50 \mathrm{~g}$ (1.91 mmol) of $\mathrm{A}_{2} 18 \mathrm{C} 6$ in $10 \mathrm{ml}$ of toluene was heated in a closed capsule at $130^{\circ} \mathrm{C}$ for $12 \mathrm{~h}$. The progress of the reaction was controlled by TLC on aluminum oxide using toluenc/ THF (3:1). After completion of the reaction (12 h), the solution was purified by filtration and washed with hot toluene. All toluene solutions were concentrated and the residues separated by chromatography either on aluminum oxide with toluene/THF $(1: 3)$ or by flash chromatography on silica gel (Kicsclgel 60 Merck 9385) with toluene/THF (1:1) and subsequently with THF/pyridine $(10: 1)$ to give as a first fraction $0.36 \mathrm{~g}(50 \%)$ of $(\mathrm{AQNet})_{2} \mathrm{~A}_{2} 18 \mathrm{C} 6$ (red solid powder) and as a second fraction $0.20 \mathrm{~g}(20 \%)$ of (AQNet) $\mathrm{A}_{2} 18 \mathrm{C} 6$ (red oil).

(AQNet)A ${ }_{2} 18 \mathrm{C} 6:{ }^{1} \mathrm{H}$ NMR $\left(\mathrm{CDCl}_{3}\right): \delta=2.83(\mathrm{t}, 12 \mathrm{H}) ; 3.61(\mathrm{t}$, $16 \mathrm{H}) ; 7.48(\mathrm{~m}, 2 \mathrm{H}) ; 7.72(\mathrm{~m}, 3 \mathrm{H}) ; 8.15(\mathrm{~m}, 2 \mathrm{H}) ; 9.71(\mathrm{~s}, 1 \mathrm{H})$.

$\mathrm{C}_{28} \mathrm{H}_{36} \mathrm{~N}_{3} \mathrm{O}_{6}$ (511.6) Calcd. C $65.73 \mathrm{H} 7.29 \mathrm{~N} 8.21$ O 18.76 Found C 65.9 H 7.4 N $8.0 \quad$ O 19.0

(AQNet) $)_{2} \mathrm{~A}_{2} 18 \mathrm{C} 6:{ }^{1} \mathrm{H}$ NMR $\left(\mathrm{CDCl}_{3}\right): \delta=2.8_{3}(\mathrm{t}, 16 \mathrm{H}) ; 3.6_{1}(\mathrm{~m}$, $16 \mathrm{H}) ; 7.4_{8}(\mathrm{~m}, 4 \mathrm{H}) ; 7.7_{2}(\mathrm{~m}, 6 \mathrm{H}) ; 8.1_{5}(\mathrm{~m}, 4 \mathrm{H}) ; 9.7_{1}(\mathrm{~s}, 2 \mathrm{H})$.

\section{$\mathrm{C}_{44} \mathrm{H}_{48} \mathrm{~N}_{4} \mathrm{O}_{8}$ (760.9) Calcd. C $69.45 \mathrm{H} 6.36 \mathrm{~N} 7.36 \mathrm{O} 16.82$ Found C 69.4 H $6.4 \quad$ N $7.3 \quad$ O 16.5}

1 -\{[2-(1,4,7,10,13-Pentaoxa-16-aza-16-cyclooctadecyl)ethyl]amino $-9,10$-anthracenedione [(AQNet)A18C6] was prepared by the same method used for the synthesis of (AQNet) $)_{2} A_{2} 18 C 6$. The end product was separated by column chromatography on aluminum oxide with toluene/THF $(1: 3)$ to provide (AQNet)A18C6 $(65 \%$ yield) as a red oil.

$$
\begin{array}{llllllll}
\mathrm{C}_{28} \mathrm{H}_{36} \mathrm{~N}_{2} \mathrm{O}_{7} \text { (512.6) } & \text { Calcd. C 65.73 } & \text { H } 7.09 & \text { N } 5.48 & \text { O } 21.89 \\
& \text { Found C } 65.3 & \text { H } 7.1 & \text { N } 5.6 & \text { O } 21.6
\end{array}
$$

\section{CAS Registry Numbers}

AQNetOH: 4465-58-1 / AQF: 569-06-2 / AQNetBr : 3591-05-7/ $\mathrm{A}_{2}$ 18C6: 23978-55-4 / (AQme) ${ }_{2} \mathrm{~A}_{2}$ 18C6: 127472-94-0 / (AQNet)A18C6: 127472-95-1/ (AQNet)A $18 \mathrm{C6}: 127472-96-2 !$ (AQNet) $)_{2} \mathrm{~A}_{2} 18 \mathrm{C}_{6}: \quad 127472-97-3$ (AQNet)A18C6Li ${ }^{+}$. ClO ${ }^{-}$: 
127473-03-4 / (AQNet)A ${ }_{2} 18{\mathrm{C} 6 \mathrm{Li}^{+}}^{+} \quad \mathrm{ClO}_{4}^{-}:$127473-05-6 / (AQNet) ${ }_{2} \mathrm{~A}_{2} 18 \mathrm{C}^{2} \mathrm{Li}^{+} \cdot \mathrm{ClO}_{4}^{-}: 127473-07-8 /$ (AQNet)A18C6 Mg ${ }^{2+}$. $2 \mathrm{ClO}_{4}^{-}: 127473-09-0$ / (AQNet)A $18 \mathrm{C}_{2} \mathrm{Mg}^{2+} \cdot 2 \mathrm{ClO}_{4}^{-}: 127473-$ 11-4 / (AQNet) ${ }_{2} \mathrm{~A}_{2} 18 \mathrm{C} \mathrm{Mg}^{2+} \cdot 2 \mathrm{ClO}_{4}^{-}: 127473-13-6 /(\mathrm{AQNet})-$ $\mathrm{A} 18 \mathrm{C}^{2} \mathrm{Ag}^{+} \cdot \mathrm{ClO}_{4}^{-}: 127473-15-8 /$ (AQNet)A $218 \mathrm{C}_{6} \mathrm{Ag}^{+} \cdot \mathrm{ClO}_{4}^{-}$ 127473-17-0 / (AQNet) $)_{2} \mathrm{~A}_{2}$ 18C6 $^{2} \mathrm{Ag}^{+}$. $\mathrm{ClO}_{4}^{-}:$127473-19-2 / (AQNet)A18C6 $\mathrm{Tl}^{+}$. $\mathrm{ClO}_{4}^{-}:$127473-21-6 / (AQNet)A 18C6T1 $^{+}$. $\mathrm{ClO}_{4}^{-}:$127473-23-8 / (AQNet) $)_{2} \mathrm{~A}_{2} 18 \mathrm{C} 6 \mathrm{Tl} \cdot \mathrm{ClO}_{4}^{-}: 127473-25-0$ / (AQme) ${ }_{2} \mathrm{~A}_{2} 18 \mathrm{C}^{2} \mathrm{Li}^{+} \cdot \mathrm{ClO}_{4}^{-}: 127473-27-2 /\left(\mathrm{AQNet}_{2} \mathrm{~A}_{2} 18 \mathrm{C} 6 \mathrm{Ag}^{+}\right.$. $\mathrm{ClO}_{4}^{-}:$: 127491-37-6 / (AQNet) ${ }_{2} \mathrm{~A}_{2} 18 \mathrm{C6} \cdot \mathrm{CF}_{3} \mathrm{SO}_{3} \mathrm{H}: 127491-35-4$ / (AQNet)A18C6 - HA: 127472-98-4 / (AQNet)A 18 C6 · HA : 127472-99-5 / (AQNet) ${ }_{2} \mathrm{~A}_{2}$ 18C6 · HA: 127473-00-1 / AQN . $\mathrm{HA}:$ 127473-01-2/AQmeBr: 7598-10-9/AQN: 82-45-1 $\mathrm{H}_{2} \mathrm{~N}\left(\mathrm{CH}_{2}\right)_{2} \mathrm{OH}: 141-43-5 / \mathrm{LiClO}_{4}: 7791-03-9 / \mathrm{Mg}\left(\mathrm{ClO}_{4}\right)_{2}: 10034-$ $81-8 / \mathrm{AgClO}_{4}: 7783-93-9 / \mathrm{TlClO}_{4}: 13453-40-2$

1) T. A. Kaden, Top. Curr. Chem. 121 (1984) 157.

2) F. Vögtle, Pure Appl. Chem. 52 (1980) 2405.

3) K. Maruyama, H. Sohmiya, H. Tsukube, J. Chem. Soc., Perkin Trans 1, 1986, 2069.

4) J. P. Dix, F. Vögtle, Chem. Ber. 114 (1981) 638.

5) L. Echegoyen, D. A. Gustowski, V. J. Gatto, G. W. Gokel, J. Chem. Soc. Chem. Commun. 1986, 220.

6) D. A. Gustowski, L. Echegoyen, D. M. Goli, A. Kaifer, R. A Schultz, G. W. Gokel, J. Am. Chem. Soc. 106 (1984) 1633.

7) A. Kaifer, D. A. Gustowski, L. Echegoyen, V. J. Gatto, R. A. Schultz, T. P. Cleary, C. P. Morgan, D. M. Goli, A. M. Rios, G. W. Gokel, J. Am. Chem. Soc. 107 (1985) 1958.

${ }^{8)}$ H. Bock, B. Hierholzer, F. Vögtle, G. Hollmann, Angew. Chem. 96 (1984) 74; Angew. Chem. Int. Ed. Engl. 23 (1984) 57.
${ }^{9)}$ S. Shinkai, Y. Ishikawa, H. Shinkai, T. Tsuno, H. Makishima, K. Ueda, O. Manabe, J. Am. Chem. Soc. 106 (1984) 1801.

10) L. A. Frederick, T. M. Fyles, N. P. Gurprasad, D. M. Whitfield, Can. J. Chem. 59 (1981) 1724.

11) T. Saji, I. Kinoshita, J. Chem. Soc., Chem. Commun. 1986, 716.

12) E. Ozeki, S. Kimura, Y. Imanishi, J. Chem. Soc., Chem. Commun. 1988, 1353.

13) L. E. Echegoyen, H. K. Yoo, V. J. Gatto, G. W. Gokel, L. Echegoyen, J. Am. Chem. Soc. 111 (1989) 2440.

${ }^{14)}$ R. H. Thomson, Naturally Occuring Quinones, 2 nd ed., Academic Press, New York 1971.

15) K. C. Murdock, R. G. Child, P. F. Fabio, R. B. Angier, R. E Wallace, F. E. Durr, R. V. Citarella, J. Med. Chem. 22 (1979) 1024.

16) B. R. J. Abadella, J. Fisher, Environ. Health 64 (1985) 1985.

${ }^{17)}$ H. Maeda, S. Furuyoshi, Y. Nakatsuji, M. Okahara, Bull. Chem. Soc. Jpn. 56 (1983) 212.

${ }^{18)}$ G. Valkanas, H. Hopff, J. Org. Chem. 27 (1962) 3680.

19) F. Vögtle, U. Elben, Chem. Ber. 111 (1978) 1434.

${ }^{20)}$ J.-C. Rodriguez-Ubis, B. Alpha, D. Plancherel, J.-M. Lehn, Helv. Chim. Acta 67 (1984) 2264

${ }^{21)}$ H. Inoue, T. Hoshi, J. Yoshino, Y. Tanizaki, Bull. Chem. Soc. Jpn. 45 (1972) 1018.

22) R. H. Peters, H. H. Sumner, J. Chem. Soc. 1953, 2101.

23) Z. Yoshida, F. Takabayashi, Tetrahedron 24 (1968) 933.

24) R. Bergter, T. Ossowski, H. Schneider, to be published.

${ }^{25)}$ B. G. Cox, P. Firman, H. Horst, H. Schneider, Polyhedron 2 (1983) 343 .

26) T. Fujinaga, I. Sakamoto, J. Electroanal. Chem. 73 (1976) 235.

$[28 / 90]$ 